\title{
Body Image Dissatisfaction Among Third, Fourth, and Fifth Grade Children
}

\author{
Karen M. Skemp-Arlt, Keely S. Rees, Richard P. Mikat, Elizabeth E. Seebach \\ University Wisconsin - La Crosse
}

\begin{abstract}
Body image dissatisfaction has become increasingly more prevalent among the preadolescent population over recent years. This study examines the level of body image dissatisfaction among 261 third, fourth, and fifth grade girls and boys. A pictorial scale was used to assess how the participants viewed their current body shape, their ideal body shape, and what they believed to be the ideal body shape of the opposite gender. Overall results indicated that $50.6 \%$ of the children surveyed were dissatisfied with their current body shape, $41.8 \%$ wanted to be thinner, while $8.8 \%$ wanted to be larger. Fifty percent of the girls were dissatisfied with their current body shape, with $45.1 \%$ wishing to be thinner. Boys showed similar trends, with $48.9 \%$ dissatisfied and $38.9 \%$ wishing to be thinner. A greater percentage of boys wanted to be larger than their current body shape (12.3\%) compared to girls (4.9\%). A significant difference was found between genders regarding the difference between scores of their current self and ideal self, where girls selected a smaller ideal body shape than the boys. An encouraging finding was that the level of body dissatisfaction decreased from third grade to fifth grade among both genders. Girls, however, still wished to be thinner over time. Boys, on the other hand, indicated a preference for a somewhat larger body shape over time. These results indicate that body image dissatisfaction exists prior to adolescence among this sample of children. Prevention strategies and education are encouraged among this age group.
\end{abstract}

(c) 2006 Californian Journal of Health Promotion. All rights reserved.

Keywords: body image, child health, body shape, gender

\section{Introduction}

Body image dissatisfaction is defined as the subjective feelings of dissatisfaction with one's physical appearance (Littleton \& Ollendick, 2003). Studies support that college-aged women perceive their figures to be heavier than what they view as ideal (Fallon \& Rozin, 1985). More recently, several studies focus on the weight concerns, body dissatisfaction, and ideal bodysize beliefs found among adolescents and children. It has been reported that children as young as five and six years old prefer body figures thinner than their own (Collins, 1991; Davison, Markey, \& Birch, 2000; Davison, Markey, \& Birch, 2003; Hendy, Gustitus, and Leitzel-Schwalm, 2001). Davison, Markey, and Birch (2000) found that 21\% of five year old girls were dissatisfied with their bodies and were concerned about their weight. Collins (1991) found that among six and seven-year-olds, $42 \%$ of girls preferred body figures thinner than their own. This trend appears to increase with age.
Research shows that by middle childhood, this number increases to over 50\% among girls (Schur, Sanders, \& Steiner, 2000). Young boys also display body image dissatisfaction (Cohane \& Pope, 2001). In a survey of ideal body-size beliefs and weight concerns of 817 fourth grade girls and boys, Thompson, Corwin, and Sargent (1997) found that $51 \%$ of white females and $46 \%$ of black females and $28 \%$ of white males and $32 \%$ of black males selected ideal body sizes thinner than their current size. Similarly, in a study of eight to 10-year-olds, Wood, Becker, and Thompson (1996) revealed that 55\% of girls and $35 \%$ of boys were dissatisfied with their weight. In a sample of over 200 eight-year-old children, Shapiro, Newcomb, and Loeb (1997) reported that $23 \%$ of girls and $18 \%$ of boys said they "always" wished they were thinner.

In this study the researcher examines the level of body image dissatisfaction among a sample of preadolescent children. It is apparent that 
pressures toward "thinness" and an ideal body shape increase as children reach adolescence, therefore, the purpose of this study was to examine whether pre-adolescent children exhibit any trend toward an "ideal body image," and if so, at what age do these trends begin to manifest.

\section{Method}

\section{Subjects}

Participants included 261 pre-adolescent children from public and parochial schools. Permission to participate in the study was obtained through letters to parents. All procedures were approved by the Institutional Review Board for the Protection of Human Subjects. The sample consisted of female $(\mathrm{n}=122)$ and male $(\mathrm{n}=139)$ children from grades third $(n=92)$, fourth $(n=80)$, and fifth $(n=89)$. The average age of the participants was 9.5. The average body mass index (BMI) for all of the girls was 18.2 and the average BMI for all of the boys was 18.7 .

\section{Instrumentation}

A pictorial instrument of child figures was used to assess body image perceptions (Figure 1). This scale was developed and validated in previous research (Collins, 1991) and consisted of seven male and seven female child figures illustrating body weight ranging from very thin to obese.
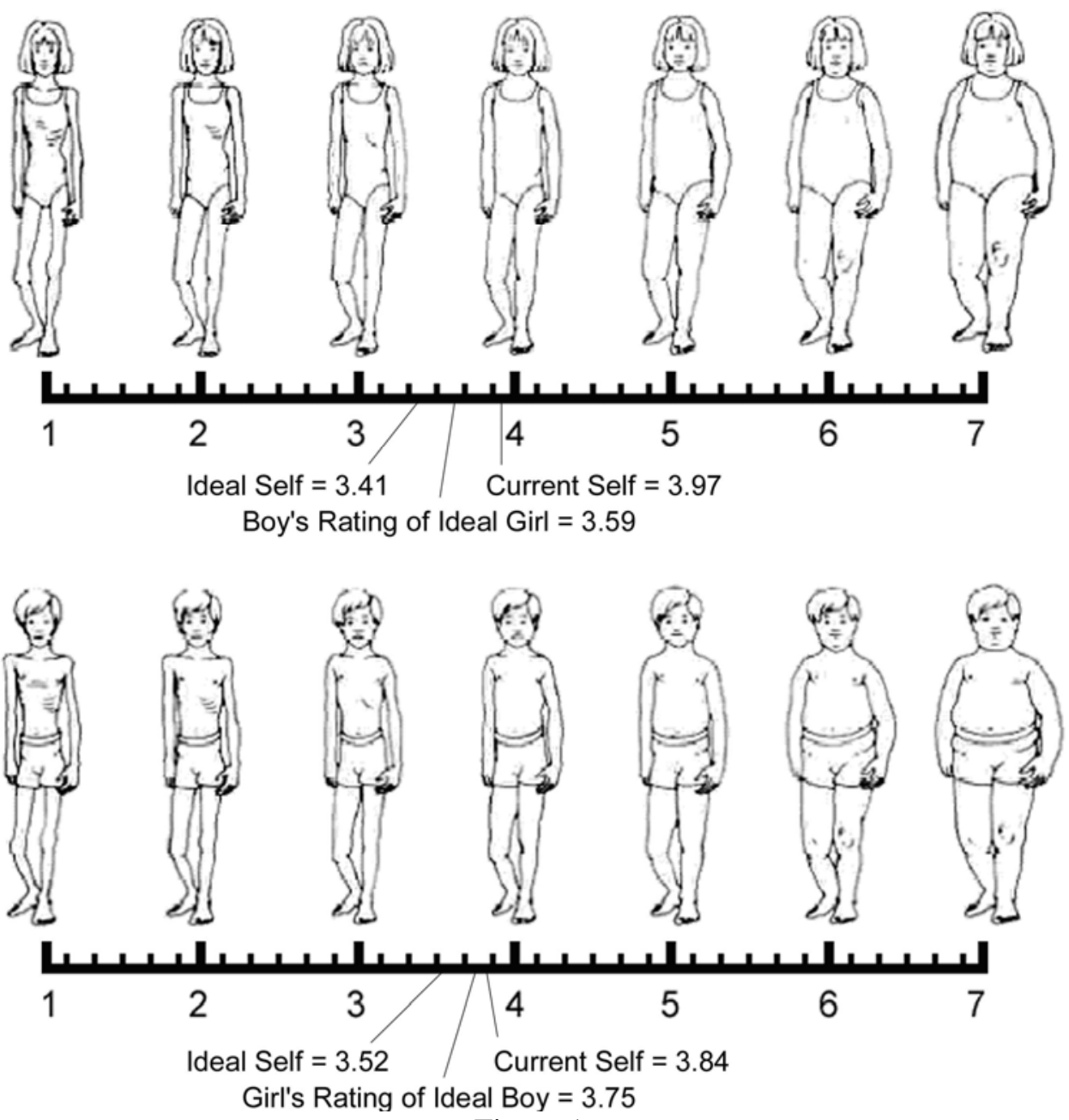

Figure 1

Mean Scores for Figure Selections of Current Self, Ideal Self, and Ideal for Opposite Gender 


\section{Procedure}

The investigator met one on one with each child. The child was asked to use the pictorial instrument to make three figure selections:

1. Self: Which picture looks the most like you? (Same gender) This question was used to assess the child's current figure.

2. Ideal: Which picture shows the way you want to look? (Same gender) This question was used to assess the child's ideal figure.

3. Ideal Other Child: Which picture shows the way you think is best for girls/boys to look? (Other gender).

Each response was scored on a 7-point scale, with 1 representing the thinnest figure and 7 representing the largest figure. The scale was not visible to the participants.

\section{Data Analysis}

Data were entered and analyzed using the Statistical Package for Social Sciences (SPSS). Multiple analysis of variance (MANOVA) was used to examine differences between gender and grade on the following five variables: current self; ideal self; ideal figure for opposite gender; current self minus ideal self; and body mass index (BMI). The significance level for all analysis was set at .05 .

\section{Results}

Body image dissatisfaction was determined by the formula, current figure - ideal figure. A positive number represents the desire to be thinner (current - ideal $>0$ ), while a negative number represents a desire to be larger (current - ideal $<0$ ).

Overall results indicated that $50.6 \%$ of the children surveyed were dissatisfied with their current body shape or size (their current figure differed from their ideal figure), $41.8 \%$ wanted to be thinner, while $8.8 \%$ wanted to be larger. Fifty percent of the girls were dissatisfied with their current body shape, with $45.1 \%$ wishing to be thinner. Boys showed similar trends, with 48.9\% dissatisfied and $38.9 \%$ wishing to be thinner. A greater percentage of boys wanted to be larger than their current body shape (12.3\%) compared to girls (4.9\%). Figure 2 shows the percentage of body dissatisfaction by grade.

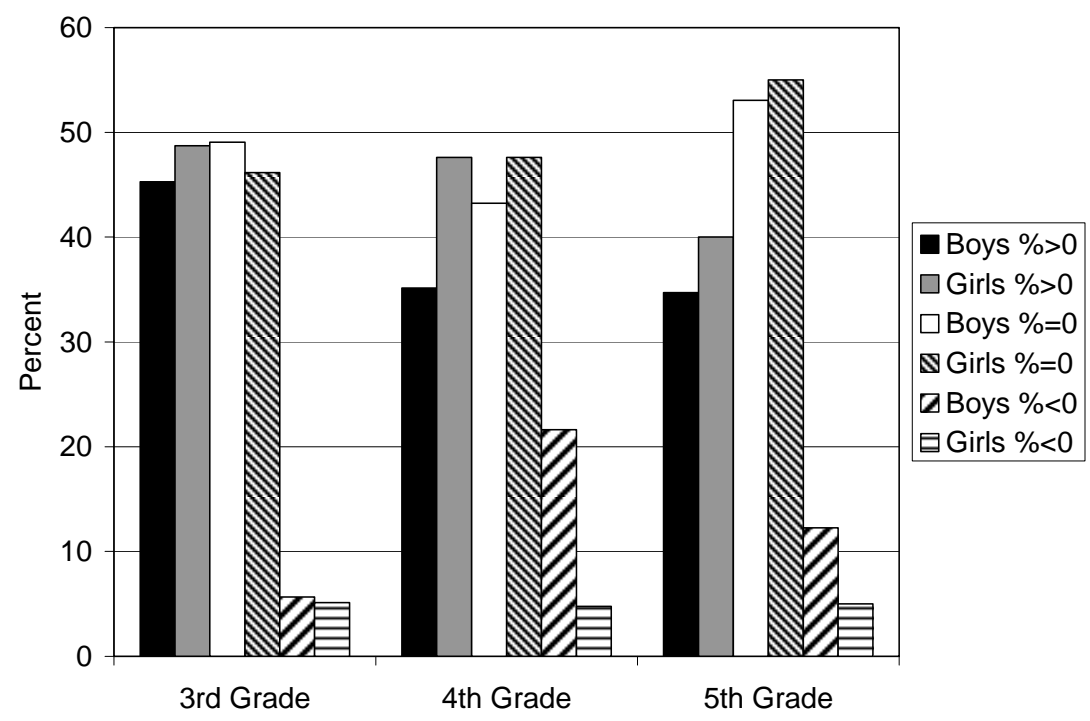

Figure 2

Percentage of Body Dissatisfaction by Grade 
Body image dissatisfaction was determined by the formula, current figure - ideal figure. A positive number represents the desire to be thinner (current - ideal $>0$ ), while a negative number represents a desire to be larger (current - ideal < 0). Body image satisfaction is represented by current size - ideal size $=0$.

When asked, "Which figure looks most like you," mean scores for all of the girls combined was $3.97(\mathrm{SD}=.08)$ and for all of the boys combined was 3.84 (SD = .07). When asked, "Which figure shows the way you want to look," mean scores for all of the girls was 3.41 (SD = $.08)$ and for all of the boys was $3.52(\mathrm{SD}=.06)$. Lastly, when asked, "Which figure do you think is best for the opposite gender to look," the girls selected a mean score of $3.75(\mathrm{SD}=.06)$ for the boys, while the boys selected a mean score of 3.59 (SD $=.05)$ for the girls. The mean scores for figure selections of Current Self, Ideal Self, and Ideal-Opposite Gender are provided in Table 1.

MANOVA results indicated a significant difference between grades regarding ideal self (how the participants want to look) ( $\mathrm{p}=.008)$. Tukey Post hoc comparison indicated that the difference was significant between grades 3 and $5(\mathrm{p}=.011)$ where third grade children (girls and boys combined) selected a mean score for ideal self of 3.28 (SD = .09), while fifth grade children selected a mean score of 3.62 (SD $=.08$ ). Table 1 shows mean score selections and standard deviations by grade for girls and boys combined.

Table 1

Mean Score Selections and Standard Deviations by Grade for Girls and Boys Combined

\begin{tabular}{|l|l|l|l|l|l|}
\hline $\begin{array}{c}\text { Girls and Boys } \\
\text { Combined }\end{array}$ & Current Self & \multicolumn{1}{|c|}{ Ideal Self } & $\begin{array}{c}\text { Ideal Figure } \\
\text { for Opposite } \\
\text { Gender }\end{array}$ & $\begin{array}{c}\text { Current Self } \\
\text { minus Ideal } \\
\text { Self }\end{array}$ & \multicolumn{1}{|c|}{ BMI } \\
\hline 3rd Grade & $3.86(.09)$ & $3.28(.09)^{*}$ & $3.59(.07)$ & $.58(.09)$ & $18.08(.29)$ \\
\hline 4th Grade & $3.90(.10)$ & $3.51(.08)$ & $3.70(.07)$ & $.39(.12)$ & $18.3(.36)$ \\
\hline 5th Grade & $3.94(.09)$ & $3.62(.08)^{*}$ & $3.72(.06)$ & $.33(.08)$ & $19.11(.37)$ \\
\hline
\end{tabular}

$* \mathrm{p}=.011$

Table 2 shows mean score selections and standard deviations for the five variables for girls by grade and for boys by grade. A significant difference was found between genders in regards to what they view as what is best for the opposite gender to look like $(\mathrm{p}=$ .039). Girls selected a mean score of 3.75 (.06) as an ideal figure for the boys, while the boys selected a mean score of $3.59(.05)$ as an ideal figure for the girls. Additionally, a significant difference was found between genders regarding the difference between current self minus ideal self $(p=.025)$. Mean score for current self among girls was 3.97 while the mean score for ideal self was 3.41, resulting in a difference of .56. The mean score for current self among boys was 3.84 while the mean score for ideal self was 3.52, resulting in a difference of .32. Table 2 shows mean score selections and standard deviations by gender and grade. Figure 3 shows mean score selections by gender and grade for Current Self, Ideal Self, and Ideal for Opposite Gender. 
Table 2

Mean Score Selections and Standard Deviations by Gender and Grade.

\begin{tabular}{|c|c|c|c|c|c|}
\hline Gender & Current Self & Ideal Self & $\begin{array}{c}\text { Ideal Figure } \\
\text { for Opposite } \\
\text { Gender }\end{array}$ & $\begin{array}{c}\text { Current Self } \\
\text { minus Ideal } \\
\text { Self } \\
\end{array}$ & BMI \\
\hline \multicolumn{6}{|l|}{ Girls } \\
\hline 3rd Grade & $3.77(.15)$ & $3.13(.14)$ & $3.62(.10)$ & $.64(.15)$ & $17.83(.38)$ \\
\hline 4th Grade & $4.09(.12)$ & $3.49(.13)$ & $3.79(.09)$ & $.60(.17)$ & $18.49(.51)$ \\
\hline 5th Grade & $4.03(.13)$ & $3.60(.12)$ & $3.85(.09)$ & $.43(.11)$ & $18.37(.42)$ \\
\hline All Girls & $3.97(.08)$ & $3.41(.08)$ & $3.75(.06)^{*}$ & $.56(.09)^{* *}$ & $18.23(.26)$ \\
\hline \multicolumn{6}{|l|}{ Boys } \\
\hline 3rd Grade & $3.92(.11)$ & $3.40(.11)$ & 3.57 (.09) & $.53(.12)$ & $18.28(.41)$ \\
\hline 4th Grade & $3.68(.16)$ & $3.54(.11)$ & $3.59(.11)$ & $.14(.17)$ & $18.08(.51)$ \\
\hline 5th Grade & $3.88(.12)$ & $3.63(.10)$ & $3.61(.09)$ & $.24(.10)$ & $19.73(.56)$ \\
\hline All Boys & $3.84(.07)$ & $3.52(.06)$ & $3.59(.05)^{*}$ & $.32(.07)^{* *}$ & $18.74(.29)$ \\
\hline
\end{tabular}

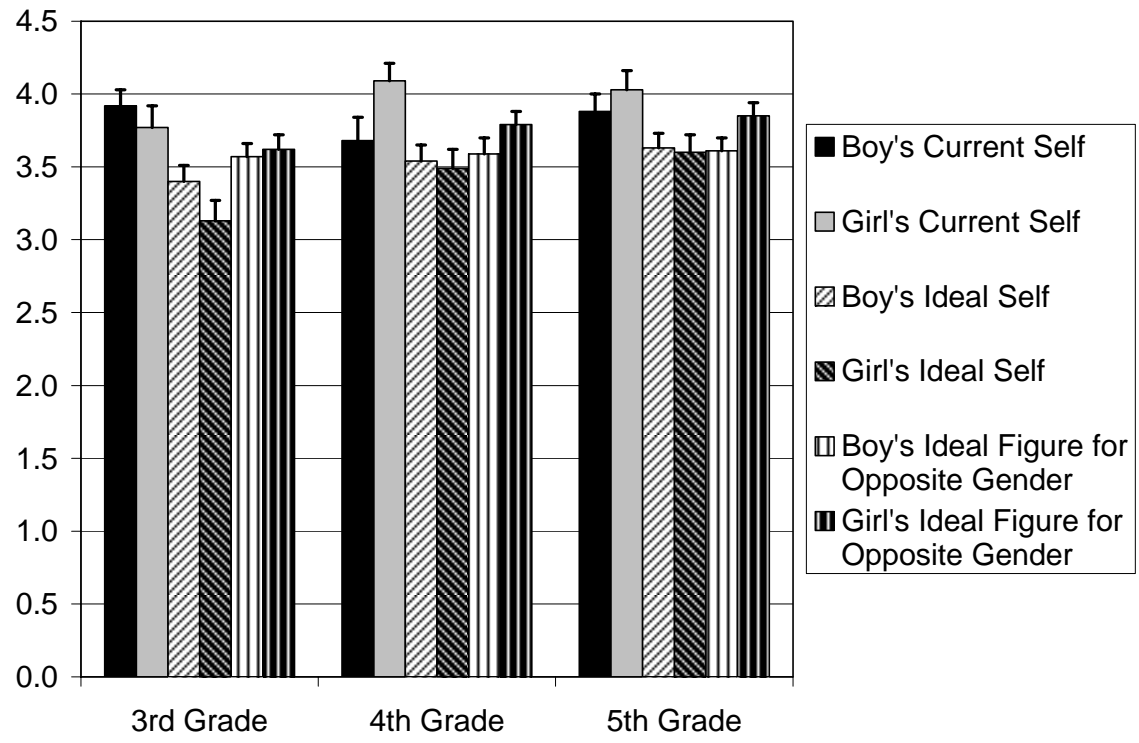

Figure 3

Mean Score Selections by Gender and Grade for Current Self, Ideal Self, and Ideal for Opposite Gender

When examining the level of body dissatisfaction by grade, $48.7 \%$ of third grade girls and $45.3 \%$ of third grade boys wanted to be thinner than their current body shape, while $5.1 \%$ of girls and $5.7 \%$ of boys wanted to be larger. $46.2 \%$ of third grade girls and $49 \%$ of third grade boys were satisfied with their body image (current self $=$ ideal self). By fifth grade, $40 \%$ of the girls and $34.7 \%$ of the boys wanted to be thinner than their current body shape, while $5 \%$ of girls and $12.3 \%$ of boys wanted to be larger. The level of body satisfaction 
increased from third to fifth grade among both the girls and the boys, where 55\% of the girls and $53.1 \%$ of the boys were satisfied with their body shape (see Figure 2).

The average BMI for all of the girls in the present study was 18.2. According to the growth charts for height to weight (BMI for-agepercentiles) from the Center for Disease Control and Prevention, 12 this is below the 75th percentile for a 9.5 year old. The average BMI for all of the boys was 18.7, which falls below the 85th percentile. By definition, a child is classified as obese if his or her BMI falls at or above the 95th percentile and is at risk of becoming overweight or obese if his or her BMI falls between the 85th and 95th percentile. On average, the children who participated in the present study fell within the normal weight range for their age and gender. When further analyzing BMI from each grade, again, both genders fell within the normal weight range for age and gender.

\section{Discussion}

These results are similar to other studies and indicate that children as young as eight years old are experiencing some level of body image dissatisfaction. Among girls, this bias toward thinness is similar to those experienced by adolescent and college-age females. The boys' level of dissatisfaction is similar to previous studies with this age group, (Collins, 1991; Shapiro, Newcomb, and Loeb, 1997; Thompson, Corwin, and Sargent, 1997), however the direction of the dissatisfaction (wishing to be thinner) is in the opposite direction than adolescent and college-age males (Cohn, Adler, Irwin, Millstein, Kegeles, \& Stone; 1987; Fallon \& Rozin, 1985).

Studies support that females, particularly white females, show a strong desire for thinness regardless of age or despite being of normal weight, while males on the other hand are more likely to express a desire for a more muscular physique. This desire for the ideal male figure, however, generally does not occur until adolescence (Smolak, 2004). The results of the present study support this trend, where $45.1 \%$ of the girls surveyed, showed a desire toward a thinner body type, despite the fact that they were of normal weight. A large percentage of boys in the present study also showed a desire toward thinness; however, $12 \%$ indicated that they wished to be larger. This would support the suggestion found in the literature that preadolescent boys (younger than 11 years old) are not yet interested in building muscle (PolceLynch, Myers, Kilmartin, Forssmann-Falck, \& Kliewer, 1998).

When looking at figure selections of an ideal body shape across grades (girls and boys combined), we found that third grade children selected a much smaller ideal figure than what the fifth grade children selected. In other words, the gap between current self and ideal self narrowed as the children got older. This was an interesting finding, and somewhat contrary to what previous studies support, which indicates that as children approach adolescence, the incidence of body image dissatisfaction increases. Overall statistics from the present study do not support this. We see that the difference or gap between current self and ideal self decreases among both girls and boys as they get older, but more so among the boys. One might surmise that as the boys are getting older and approaching the age of 11 years, they are beginning to show less desire for a smaller physique. This fact alone could be one reason that the overall change in ideal self figure selections occurred.

When examining overall body dissatisfaction across grades by gender, our results showed that as girls got older (from third grade to fifth grade), the desire for thinness decreased and their level of body satisfaction increased. Similarly, boys showed a decrease in wishing to be thinner as they got older; however, they did exhibit an overall trend toward wishing to be larger from third to fifth grade. Body satisfaction among boys also increased from third grade to fifth grade. These are encouraging findings and go against what is found in previous literature. These results should be viewed with guarded optimism, however, because the overall level of body dissatisfaction among the children as a whole was still high. 
When examining results between genders with all grades combined, as mentioned, there were a large percentage of boys who expressed a desire toward a thinner body shape. However, the difference between the selection of current body figures and ideal body figures was greater and more obvious for the girls than was for the boys. The girls' selection of their current body figure closely resembled a four on the pictorial scale. This figure selection was exactly in the middle of the scale, with three smaller body figures and three larger body figures. The girls selected a figure that was a full size smaller on the scale as ideal. The boys also selected the same current body figure, but their selection of an ideal figure was still close to the middle of the scale. What is causing this greater desire toward thinness among young females? Could it be that society promotes a thin, ideal body size for women? Fredrickson and Robertson (1997) refer to this as the "objectification theory," in which cultural images objectify women as thin, sexy, and virtually flawless, which therefore put pressures on young girls to attain an ideal body size and shape. On the other hand, a cultural ideal of muscularity is emerging among males, which puts pressure on young boys to try to attain a muscular ideal. Perhaps future investigations should include questions as to why these children desire a thinner (or larger) body size. Furthermore, for the boys who selected a larger size it should be better defined as to what "larger" means to them.

Hendy, Gustitus, and Leitzel-Schwalm (2001) found that by the ages of six to eight, gender differences in attitudes about ideal body figures begin to appear. Girls are more likely to show more body dissatisfaction, more belief that thin is "likeable" and more desire to "be thinner." This may be evidenced in the difference between the girls' and boys' selection of an ideal body figure for girls. The boys' selection for the ideal body figure for girls was not as thin as what the girls selected as an ideal body size for their own gender, perhaps indicating that the boys have not yet developed the perception of the thin physique for girls or perhaps are not yet influenced by the cultural images of thinness. Girls' selection of an ideal figure for the boys tended to hover around the middle figure selection, and this selection was slightly larger than what the boys deemed ideal for their own gender. Perhaps this is another indicator that girls may be starting to be influenced by the cultural messages of "bigness" for boys. Or perhaps, girls may be feeling pressure at a younger age from other outside influences, such as peers, their selection of role models, media influences, or early maturation. Or it may simply be a reflection of the greater societal emphasis on women's rather than men's bodies.

Parental consent was obtained for all children who participated in this study. Therefore, there may be somewhat of a selection bias in the sample of participating children. It is believed that parents who did not give consent may have denied participation because their child was overweight or underweight and did not want to bring further attention to their body shape and size. This is speculation, however, is substantiated from informal comments to the researcher. Furthermore, the participating schools consisted mostly of Caucasian, middle class students. Therefore, extrapolation of results to a larger, more diverse sample of children may be limited.

\section{Conclusion}

It is disturbing that these children are showing trends toward wanting to be "thinner" than their current size and shape. An encouraging finding from the present study showed that the ideal body image was getting "less small" over time. However, much of the research supports that body image dissatisfaction increases with age and peaks during early adolescence, particularly among females (Adams, Katz, Beaucham, Cohen, \& Zavis, 1993). It is further substantiated in the literature that the use of unhealthy dieting techniques used to control weight increases with the adolescent population. Body image dissatisfaction is one of several precipitants for the development of disturbed eating behaviors and clinical eating disorders (Skemp-Arlt, 2006). Prevention and education may be indicated for preadolescents before consequences associated with body image dissatisfaction, such as disturbed eating patterns, manifest. Emphasis should be placed on empowering preadolescent children to recognize 
and resist the cultural messages that they are exposed to. Prevention programs should include a variety of factors. These factors can include education on developmental changes that occur with puberty; genetic influences; critical thinking regarding mass media messages that contribute to body dissatisfaction; dangerous effects of unhealthy dieting practices; and learning of self-acceptance, life skills, and healthy coping mechanisms (Kater, Rohwer, \& Londre, 2002). For additional resources and prevention education ideas, see Table 3 and Kater (2004, 2005).

Table 3

Additional Resources

\begin{tabular}{|l|l|}
\hline \multicolumn{1}{|c|}{ Resource } & \multicolumn{1}{c|}{ Web Address } \\
\hline BodyImageHealth.org & $\underline{\text { http://www.bodyimagehealth.org }}$ \\
\hline Center for Media Literacy & $\underline{\text { http://www.medialit.org }}$ \\
\hline Dads and Daughters & $\underline{\text { http://www.dadsanddaughters.org }}$ \\
\hline Eating Disorders Awareness and Prevention & $\underline{\text { http://www.edap.org }}$ \\
\hline Girl Power & $\underline{\text { http://www.health.org/power }}$ \\
\hline Go Girls Program, National Eating Disorders Association & $\underline{\text { http://www.neda.org }}$ \\
\hline Harvard Eating Disorder Center & $\underline{\text { http://www.hedc.org }}$ \\
\hline Healthy Weight Network & $\underline{\text { http://www.healthyweight.net }}$ \\
\hline
\end{tabular}

\section{References}

Adams, P. J., Katz, R. C., Beauchamp, K., Cohen, E., Zavis, D. (1993). Body dissatisfaction, eating disorders, and depression: A developmental perspective. Journal of Child and Family Studies, 2, 37-46.

Cohane, G. H., Pope, Jr., H. G. (2001). Body image in boys: A review of the literature. International Journal of Eating Disorders, 29, 373-379.

Cohn, L. D., Adler, N. E., Irwin Jr., C. E., Millstein, S. G., Kegeles, S. M., Stone, G. (1987). Body-figure preferences in male and female adolescents. Journal of Abnormal Psychology, 96(3), 276-279.

Collins, M. E. (1991). Body figure perceptions and preferences among preadolescent children. International Journal of Eating Disorders, 10, 199-208.

Davison, K. K., Markey, C. N., Birch, L. L. (2000). Etiology of body dissatisfaction and weight concerns among 5-year-old girls. Appetite, 35, 143-151.

Davison, K. K., Markey, C. N., Birch, L. L. (2003). A longitudinal examination of patterns in girls' weight concerns and body dissatisfaction from ages 5 to 9 years. International Journal of Eating Disorders, 33, 320-332.

Fallon, A. E., Rozin, P. (1985). Sex differences in perceptions of desirable body shape. Journal of Abnormal Psychology, 94, 102-105.

Frederickson, B. L., Roberts, T. A. (1997). Objectification theory: Toward understanding women's lived experiences and mental health risks. Psychology of Women Quarterly, 21, 173-206.

Hendy, H. M., Gustitus, C., Leitzel-Schwalm, J. (2001). Social cognitive predictors of body image in preschool children. Sex Roles, 44, 557-569.

Kater, K., Rohwer, J., \& Londre, K. (2002). Evaluation of an upper elementary school program to prevent body image, eating and weight concerns. Journal of School Health, 72, 199-205.

Kater, K. (2004). Real kids come in all sizes: 10 essential lessons to build your child's body esteem. New York: Broadway Books.

Kater, K. (2005). Healthy body image: Teaching kids to eat and love their bodies too! Curriculum for grades 4 -6. Retrieved September 1, 2006, from http://www.bodyimagehealth.org/resources.html 
Littleton, H. L., Ollendick, T. (2003). Negative body image and disordered eating behavior in children and adolescents: What places youth at risk and how can these problems be prevented? Clinical Child Family Psychology, 6, 51-66.

Polce-Lynch, M., Myers, B., Kilmartin, C., Forssmann-Falck, R., Kliewer, W. (1998). Gender and age patterns in emotional expression, body image, and self-esteem: A qualitative analysis. Sex Roles, 38, 1025-1041.

Schur, E. A., Sanders, M., Steiner, H. (2000). Body dissatisfaction and dieting in young children. International Journal of Eating Disorders, 27, 74-82.

Shapiro, S., Newcomb, M., Loeb, T. B. (1997). Fear of fat, disregulated-restrained eating, and bodyesteem: Prevalence and gender differences among eight to ten year old children. Journal of Clinical Child Psychology, 26, 358-365.

Skemp-Arlt, K. M. (2006). Body image dissatisfaction and eating disturbances among children and adolescents: Prevalence, risk factors, and prevention strategies. Journal of Physical Education Recreation and Dance, 77(1), 45-51.

Smolak, L. (2004). Body image in children and adolescents: Where do we go from here? Body Image, 1, 15-28.

Thompson, S. H., Corwin, S. J., Sargent, R. G. (1997). Ideal body size beliefs and weight concerns of fourth-grade children. International Journal of Eating Disorders, 21, 279-284.

Wood, K. C., Becker, J. A., Thompson, J. K. (1996). Body image dissatisfaction in preadolescent children. Journal of Applied Developmental Psychology, 17, 85-100.

Author Information

Karen M. Skemp-Arlt, Ph.D., Assistant Professor*

Exercise and Sport Science Department

134 Mitchell Hall

University Wisconsin - La Crosse

1725 State Street

La Crosse, WI 54601

Ph.: 608-785-8187

Fax.: 608-785-8173

E-Mail: skemp.kare@uwlax.edu

Keely S. Rees, Ph.D., Assistant Professor

Health Education/Health Promotion Department

203 Mitchell Hall

University Wisconsin - La Crosse

1725 State Street

La Crosse, WI 54601

Ph.: 608-785-8162

Fax.: 608-785-8173

E-Mail: Rees.keel@uwlax.edu

Richard P. Mikat, Ph.D., Professor

Exercise and Sport Science Department

129 Mitchell Hall

University Wisconsin - La Crosse

1725 State Street

La Crosse, WI 54601

Ph.: 608-785-8177

Fax.: 608-785-8173 


\author{
E-Mail: Mikat.rich@uwlax.edu \\ Elizabeth E. Seebach, Associate Professor \\ Psychology Department \\ 341 Graff Main Hall \\ University Wisconsin - La Crosse \\ 1725 State Street \\ La Crosse, WI 54601 \\ Ph.: 608-785-6889 \\ Fax.: 608-785-8173 \\ E-Mail: Seebach.eliz@uwlax.edu \\ * corresponding author
}

